\title{
Element soil behaviour during pile installation simulated by 2D- DEM
}

\author{
Xiaohui $\mathrm{Ji}^{1, *}$, Yi Pik Cheng ${ }^{2}$, and Junwei $\mathrm{Liu}^{3}$ \\ ${ }^{1}$ MSc student, Department of Civil, Environment \& Geomatic Engineering, University College London, London, UK \\ ${ }^{2}$ Senior Lecture, Department of Civil, Environment \& Geomatic Engineering, University College London, London, UK \\ ${ }^{3}$ Academic visitor, Department of Civil, Environment \& Geomatic Engineering, University College London, London, UK \\ Associate Professor, Qingdao Technological University, Qindao, China
}

\begin{abstract}
The estimation of the skin friction of onshore or offshore piles in sand is still a difficult problem for geotechnical engineers. It has been accepted by many researchers that the mechanism of driving piles in the soil has shared some similarities with that of an element shear test under the constant normal stiffness (CNS) condition. This paper describes the behaviour of an element of soil next to a pile during the process of pile penetration into dense fine sand using the 2D-DEM numerical simulation software. A new CNS servo was added to the horizontal boundary while maintaining the vertical stress constant. This should simulate the soil in a similar manner to that of a CNS pile-soil interface shear test, but allowing the vertical stress to remain constant which is more realistic to the field situation. Shear behaviours observed in these simulations were very similar to the results from previous researchers' lab shearing tests. With the normal stress and shear stress obtained from the virtual models, the friction angle and the shaft friction factor $\beta$ mentioned in the API-2007 offshore pile design guideline were calculated and compared with the API recommended values.
\end{abstract}

\section{Introduction}

The study of the shaft resistance of offshore piles has become a hot spot in the geotechnical engineering. It has been widely accepted that the constant normal stiffness (CNS) shear test can provide insights into the mechanism of the skin friction developed along the pile shafts. [1-5] Similar with the CNS shear tests, the frictional behaviours along the pile shaft is also significantly influenced by the behaviours of the soilsolid interface.

However, most of the CNS shear tests were conducted in the laboratory condition. These CNS tests often have high requirements on the experimental apparatus. [3] Also, due to the large scale of the pile-sand interface shear test, it is not easy to conduct the test in a laboratory. Therefore, the numerical simulation will be a better way to understand the behaviour of soil during the pile installation.

In this paper, the numeric analysis software based on the 2D discrete element method was used to conduct the CNS shear test simulation. A virtual model of the shear test with the CNS servo was established to investigate the soil behaviour. Also, the test results were compared with the data from the laboratory test. And the shaft resistance was also compared with the value recommended in the design code (API-2007) [6].

\section{CNS pile-soil interface shear test}

\footnotetext{
Xiaohui Ji: xiaohuiji211@,163.com
} 


\begin{tabular}{|c|c|}
\hline $\begin{array}{c}\text { Diameter of particles composing pile } \\
\text { surface }(\mathrm{mm})\end{array}$ & 0.18 \\
\hline $\begin{array}{c}\text { Normalized roughness of pile surface } \\
(--)\end{array}$ & 0.1 \\
\hline
\end{tabular}

\subsection{Virtual model creation}

The virtual model for the CNS pile-soil interface direct shear test was made up of four parts: soil element, pile surface, four walls and a CNS servo.

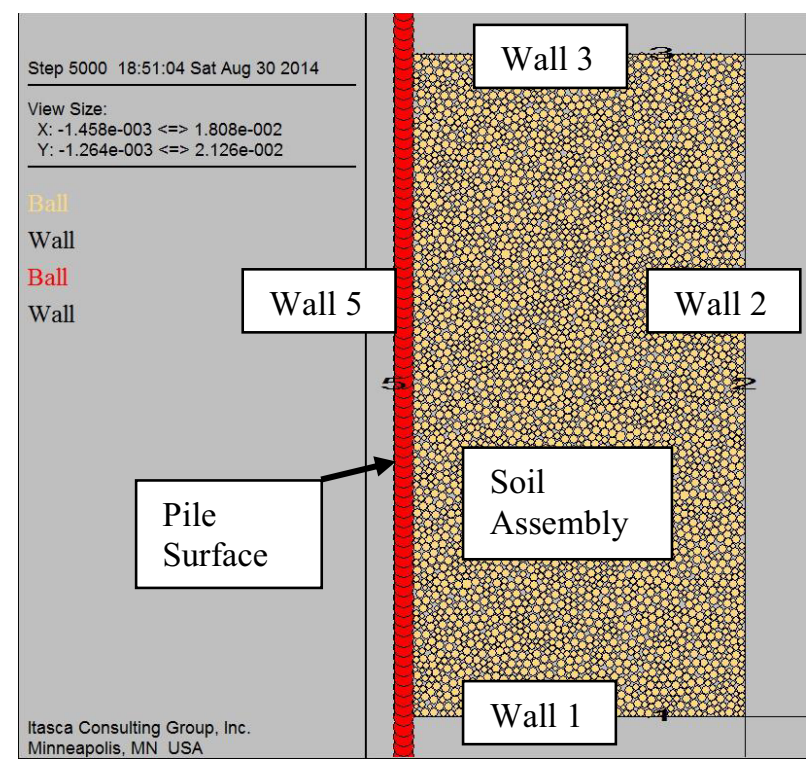

Figure 1. Model for the CNS pile-soil interface shear test

As it is shown in Figure 1, the tested soil element in the model is created as an assembly of small round balls, which stand for the sand particles. On the left of soil element, the vertical-arranged bigger balls, firmly connected with each other, composed the pile surface. Additionally, four frictionless walls around the soil element can prevent the soil particles from escaping during the simulation.

The constant normal stiffness condition during the shear test was obtained by a servo-controlled stress feedback system. This servo can automatically adjust the velocity of Wall 2 (the wall on the right side in Figure 1) to change the normal load (horizontal direction) on the soil according to the following equation with the measured stress on Wall 2.

Where,

$$
\Delta \sigma_{\mathrm{n}}=K^{*} \Delta \mu
$$

$\Delta \sigma_{\mathrm{n}}=\sigma_{\mathrm{n}}-\sigma_{\mathrm{n} 0}$ is the increment of normal stress.

$\Delta \boldsymbol{\mu}=\boldsymbol{\mu}-\boldsymbol{\mu}_{0}$ is the increment of normal displacement.

$K$ is the constant normal stiffness.

It should be clearfied that the top and bottom walls (Wall 1 and Wall 3) control the vertical stress level, which is governed by how deep the element is located. These two walls are controlled by servo-mechanisms that ensures the vertical stress remains constant, they can move allow a change in volume of the soil element. Wall 5 is frictionless and fixed during the simulation. It can prevent the pile surface from moving towards the left without disturbing the measured vertical stress (shear stress) on the pile when dense soil dilates in the shear test.

\subsection{Constant normal stiffness servo}

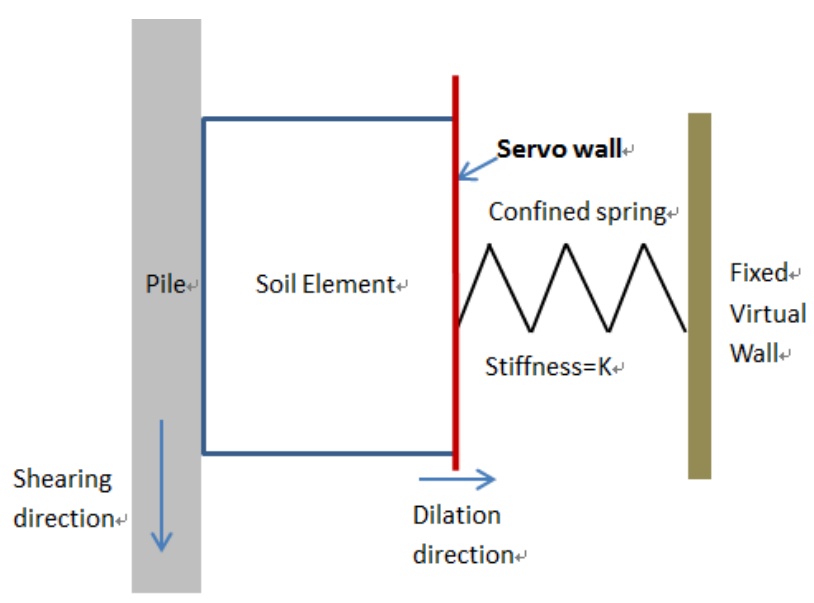

Figure 2. Schematic diagram of CNS pile-soil interface shear test

As it is shown in Figure 2, the soil sample (dense sand) will be sheared and dilated during the pile moving downward. It will result in an increase of the stress $\left(\Delta \sigma_{n}\right)$ on the servo wall (Wall 2 in the model). However, due to the confinement of the spring, the servo wall will move to the right side, and compress the spring to get an equilibrium state. During this process, the displacement of the servo wall can be noted as $\Delta \boldsymbol{\mu}$, and it can be determined by $\Delta \boldsymbol{\mu}=\Delta \sigma_{\mathrm{n}} / K$.

This equation is the base of designing the CNS servo wall. The specific algorithm is as follows:

(1) After the sample reach the initial stress condition, get the initial normal stress on the servo wall $\left(\sigma_{n_{-} \text {old }}\right)$. Then, fix Wall 5 and give a constant shearing rate $\left(\mathrm{V}_{\text {pile }}\right)$ to the pile. The shearing rate should not be too big, otherwise the unbalanced force in the soil cannot be fully dissipated.

(2) Allow the pile to move a certain time first (e.g. 10 cycles), and then stop the pile.

(3) After that, the new stress on the servo wall $\left(\sigma_{\text {nn new }}\right)$ can be obtained by using "get_ss" FISH function in the PFC2D manual [7]. Then the change of the normal stress on the servo wall can be determined, which is $\Delta \sigma_{\mathrm{n}}=\sigma_{\mathrm{n} \_ \text {new }}-\sigma_{\mathrm{n} \_ \text {old. }}$. Hence, the required displacement of the servo wall under CNS condition should be calculated as $\Delta \mu=\Delta \sigma_{\mathrm{n}} / K=$ $\left(\sigma_{\text {n_new }}-\sigma_{\text {n_old }}\right) / K$.

(4) In order to reach this required displacement, the servo wall was given a constant velocity $\left(\mathrm{V}_{\text {servo }}\right)$. This velocity also should be small enough to allow the system to reach equilibrium.

(5) After the servo wall move $\Delta \boldsymbol{\mu}$ distance, the wall will stop, and solve the unbalanced force ratio (muf/mcf) in the soil sample to reach equilibrium state. It should be noticed that during this step, the pile should also not move. 
(6) These five steps above are included in a looping statement, which can be iterated thousands of times to get the expected shear displacement.

The most important point in this CNS algorithm is that the equilibrium state should always be achieved before any movement of the pile. It can reduce the unbalanced force in the system and increase the reliability of the test. The old stress on the servo wall ( $\left.\sigma_{n_{-} \text {old }}\right)$ will always be automatically updated by the new stress $\left(\sigma_{n_{-} \text {new }}\right)$ in that last loop.

\subsection{Initial stress condition of soil element}

In this paper, two soil samples in different depths $(10 \mathrm{~m}$ and $25 \mathrm{~m}$ ) were selected to simulate the shaft resistance of pile under different normal stress conditions. The normal stress $\sigma_{\mathrm{n}}$ was determined by the one-dimensional consolidation test with 2D-DEM simulation software.

Table 2. Initial stress condition of tested samples

\begin{tabular}{|c|c|c|}
\hline Soil condition & Soil element 1 & Soil element 2 \\
\hline $\begin{array}{c}\text { Overburden stress } \sigma_{\mathrm{v}} \\
(\mathrm{kpa})\end{array}$ & 220 & 550 \\
\hline $\begin{array}{c}\text { Normal stress } \sigma_{\mathrm{n}} \\
(\mathrm{kpa})\end{array}$ & 95 & 236 \\
\hline $\begin{array}{c}\text { Input constant } \\
\text { stiffness }(\mathrm{pa} / \mathrm{m})\end{array}$ & $5.69 \mathrm{e} 8$ & $6.57 \mathrm{e} 8$ \\
\hline
\end{tabular}

\section{Results}

\subsection{Normal stiffness in the test}

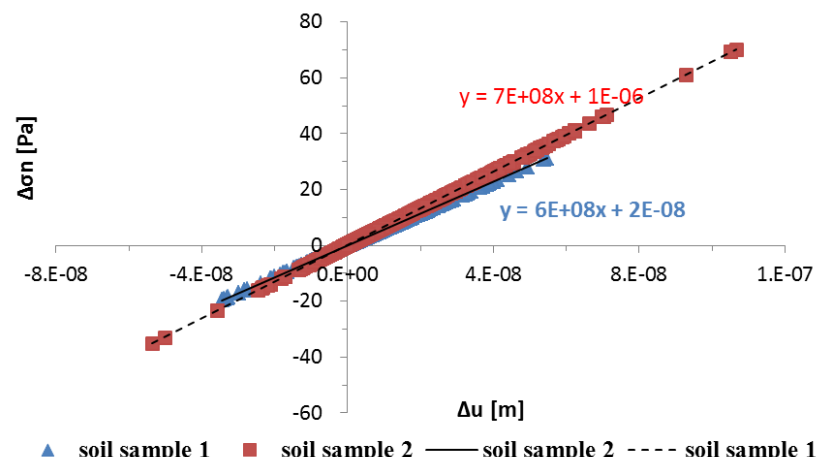

Figure 3. Typical trend of normal stiffness in the test

Figure 3 illustrated variations of normal stress on the servo wall $\left(\Delta \sigma_{\mathrm{n}}\right)$ against the variations of the wall displacement $(\Delta \boldsymbol{\mu})$ in the CNS test. It is obvious that $\Delta \sigma_{\mathrm{n}}$ shows a quite good linear relationship with $\Delta \boldsymbol{\mu}$. This means the servo wall controlled the constant normal stiffness (CNS) boundary condition very well. The slopes of the lines are the value of constant normal stiffness, which is $6 \mathrm{e} 8 \mathrm{~Pa} / \mathrm{m}$ for soil sample 1 and $7 \mathrm{e} 8$ $\mathrm{Pa} / \mathrm{m}$ for soil sample 2 respectively. These values are quite close to the input constant stiffness $(5.69 \mathrm{e} 8$ for sample $1 \& 6.57 \mathrm{e} 8$ for sample 2 ) in Table 2.

\subsection{Shear behaviour compared with lab test}

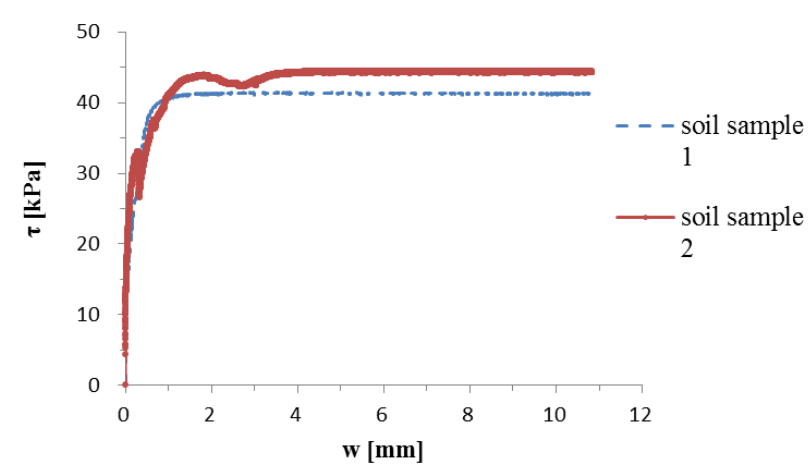

Figure 4. Shear stress from the CNS pile-soil shear test

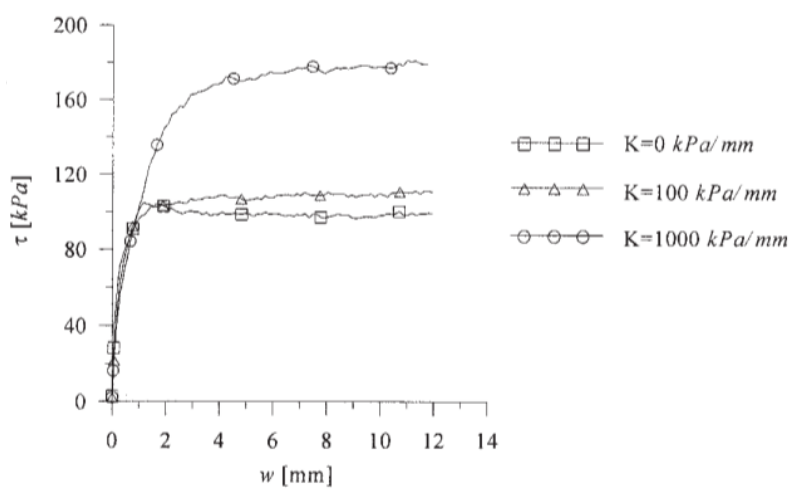

Figure 5. Shear stress from CNS lab test [1]

The shear stress obtained from the numerical simulation shown in Figure 4 shared a very similar trend with the results from the lab tests.

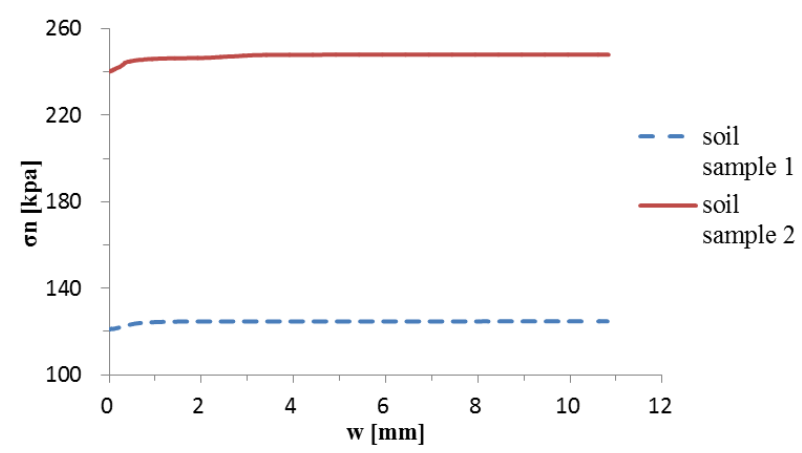

Figure 6. Variation of normal stress in CNS test

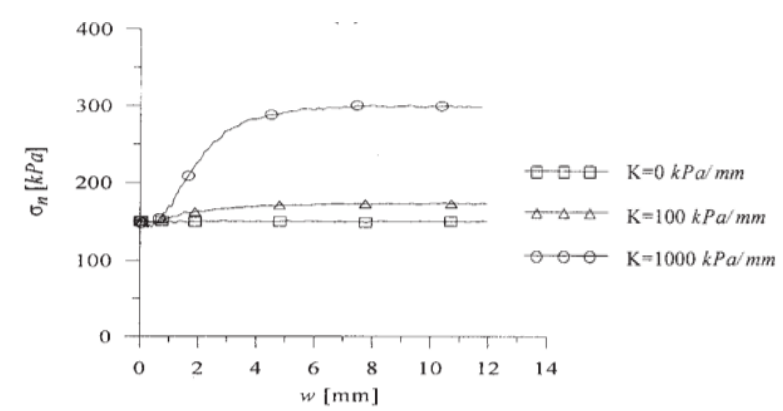

Figure 7. Normal stress in CNS lab test [1] 
Figure 6 illustrated the normal stress against shear displacement (pile displacement) in the CNS shear test, while Figure 7 shown the corresponding results from the laboratory tests (D. Porcino et. al. ,2003).

It can be noticed that the normal stress in both tests were increased slightly. In the rough surface, the dense sand tends to dilate during the direct shear. Therefore the current normal stress on the servo wall was increased, as it is shown in Figure 7. And a higher stiffness will result in a bigger increase of normal stress.

However, it should be point out that the all the soil samples from Porcino's tests have the same initial normal stress, that's why the three samples in Figure 7 concentrated at the same point at the beginning of the test. In this paper, soil sample 1 and 2 have two different normal stresses due to their different depth, so they start to increase from two different points.

\subsection{Link to the pile shaft resistance design}

The lateral earth pressure method in API-2007 noted that the skin friction of the offshore piles is determined as

Where, $\quad \tau_{f}=\mathrm{K} \sigma_{v}^{\prime} \tan \delta_{f}=\beta \sigma_{v}^{\prime}$

$\mathrm{K}$ is the coefficient of lateral earth pressure $\left(\mathrm{k}=\frac{\sigma_{h}^{\prime}}{\sigma_{v}^{\prime}}\right)$, normally equals 0.8 or 1.0 .

$\sigma_{v}^{\prime}$ is the vertical effective stress at any depth.

$\delta_{f}$ is the friction angle between the soil and pile shaft.

$\beta$ is the shaft friction factor, which is equivalent to the "K $\tan \delta_{f}$ " term.

According to the above numerical simulation results, the mobilized friction coefficient of the pile skin friction can be obtained as:

$$
\tan \delta_{\mathrm{f}}=\tau / \sigma_{\mathrm{n}}
$$

Figure 8 illustrated the variations of the mobilized friction coefficient of two soil samples against shear displacement. The $\tau / \sigma_{\mathrm{n}}$ ratio for two soil samples is 0.33 and 0.18 respectively. Therefore, the maximum mobilized friction angle for sample 1 is $18.3^{\circ}$, while for sample 2 , friction angle is $10.2^{\circ}$. The recommended friction angle in API-2007 for medium or dense sand is around $25^{\circ}$ to $30^{\circ}$, which is relatively higher than the results from the numerical simulations.

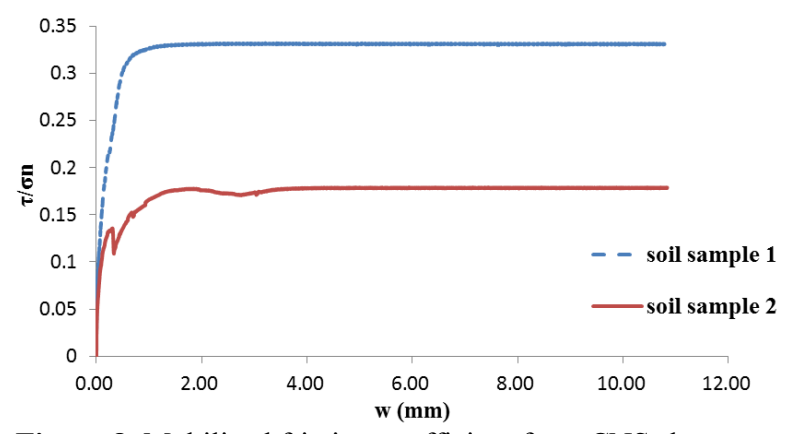

Figure 8. Mobilized friction coefficient from CNS shear test
Also, in Equation (2), if $\mathrm{K}$ equals to 0.8 , the shaft friction factor $\beta$ for sample 1 can be calculated as 0.27 and 0.14 for sample 2 , which are also relatively smaller compared with recommended value ( 0.46 for dense sand) in API-2007.

The main reason of the shear friction angle and shaft friction factor $\beta$ are both quite small, is likely because of the simulation of the sand particles is too ideal. In this paper, all the soil particles were simulated as round disks, which may reduce the roughness of the particles. Also, the influence of water could also be a possible reason, because the simulation of the soil sample is in a dry condition, but the design code is for the sand which is saturated.

\section{Conclusions}

This paper studied shaft resistance of offshore piles with discrete element method. The shaft resistance was obtained from a numeric simulation of the constant normal stiffness pile-soil interface direct shear test. The results from the tests were also analysed in details, and compared with offshore pile design codes. The following conclusions have been obtained from the tests.

1) A new method of simulating the constant normal stiffness shear test with 2D-DEM was proposed in this paper. Based on this new method, a virtual model of CNS interface shear test was created.

2) The soil sample interacted with the rough pile surface tend to dilate, which can increase the normal stress on the boundary (servo wall).

3) The initial stress condition has a big impact on the shear behaviour. The higher initial vertical stress, the higher shear stress and lower mobilized shear friction angle can be observed.

4) Although the shaft friction factor $\beta$ obtained from the 2D-DEM model is relatively smaller than the recommended values from API-2007 codes, numeric simulations of CNS interface test with DEM can still be a feasible method to study the shaft friction resistance of offshore piles if some improvements of the model were made.

\section{References}

1. D. Porcino, V. Fioravante, V.N. Ghionna, S. Pedroni Geotechnical Testing Journal. 26, 289-301 (2003)

2. L. H. Ooi, J. P. Carter Geotechnical Testing Journal, 10(1):10 (1987)

3. B. M. Lehane, D. J. White, Canadian Geotechnical Journal. 42, 1039-1052 (2005)

4. V. Fioravante, Rivista Italiana Di Geotecnica. 3, 722. (1999)

5. S. Liu, J. Wang, Geomechanics from Micro to Macro - Soga et al. (Eds), 455-458 (2015).

6. Recommended practice for planning, designing, and constructing fixed offshore platforms: working stress design. American Petroleum Institute. (2007)

7. Particle flow code $2 \mathrm{D}$ online manual. Itasca Consulting Group, Inc. Third Edition (2006). 